\title{
1. Social capital and well-being in developing countries: an introduction
}

\author{
Jonathan Isham, Thomas Kelly and \\ Sunder Ramaswamy
}

What are human investments? Can they be distinguished from consumption? Is it at all feasible to identify and measure them? What do they contribute to income? Granted that they seem amorphous compared to brick and mortar, and hard to get at compared to the investment accounts of corporations, they assuredly are not a fragment; they are rather like the contents of Pandora's box, full of difficulties and hope. (Theodore Schultz, 1961, in his address to the American Economic Association on human capital)

Forty years after the introduction of the concept of human capital in the corpus of economics, the related concept of social capital has taken hold. From an economist's perspective, social capital - like human capital before it - is a concept with much appeal and promise, but full of definitional and operational ambiguities. The concept creates challenges and opportunities for researchers, practitioners and teachers. The chapters in this volume explore these challenges and opportunities.

In assembling this volume, we asked contributors from a diverse range of academic and policy viewpoints to share new research and field experiences. Although these chapters are informed by excellent research on social capital in the developed world (for example, Putnam, 1993, 2000), the volume itself focuses on the developing world. As development and environmental economists, we feel that a volume dedicated to social capital and well-being in developing countries meets an urgent need in academic and policy quarters. The economics discipline, both scholarly and popular, continues to focus mostly on problems and challenges faced by the industrialized world (Basu, 1997). Both conceptually and operationally, we feel that economists have an obligation to draw our discipline's collective attention to 'what needs to be done' to improve the lives of the poor.

In this introductory chapter, we highlight the thematic connections among the chapters that comprise the rest of the volume. The first section of the chapter discusses the rise of the concept of social capital within the discipline of economics. The second section uses a household production framework to 
explore the conceptual relationship between social capital and well-being. The third section discusses the ideal conditions for investing in social capital. The fourth section summarizes each of the subsequent chapters.

\section{THE RISE OF SOCIAL CAPITAL}

A new Pandora's box, for better or for worse, has been opened. Despite scepticism among many mainstream economists (highlighted by Streeten in Chapter 3), the concept of social capital - defined by Woolcock in Chapter 2 as 'the networks and norms that facilitate collective action' - has worked its way into the market place of economic ideas.

The recent evidence of this trend is striking. A 'keyword' search of all journals in EconLit, the most frequently used database of references in economics, shows that citations for 'social capital' have grown rapidly over the last decade, doubling each year since the late 1990 s (Figure 1.1$).{ }^{1}$ In 2000 , social capital has about a quarter of the absolute number of citations as human capital. (The related concept, 'social networks', had only begun to show any growth.)

In fact, this recent growth of interest in social capital compares favourably with growth of interest in human capital in the years after that concept was introduced. 'Human capital' appeared as a keyword in 12.2 per cent of all 'capital' citations in EconLit in 1969, about a decade after being formally introduced by Schultz (1960). 'Social capital' appears as a keyword in 7.4 per cent of all 'capital' citations in EconLit in 2000, about a decade after being formally introduced by Coleman (1990). The establishment of a new subcategory in the Journal of Economic Literature, 'Social Norms and Social Capital' is further evidence of the discipline's revealed preference for this term.

Many prominent economists are alarmed by this trend (Arrow, 2000; Solow, 2000). While acknowledging the importance of the 'social dimension of development', these and other sceptics question whether the term 'social capital', with inconsistent and ambiguous definitions throughout the social science literature, can adequately capture the complexities of such a dimension.

Some of the loudest criticism concerns the appropriateness of the capital metaphor: are networks and norms really forms of 'capital'? In this regard, too, the concept of social capital compares favourably with the concept of human capital, which faced similar resistance when first introduced by Theodore Schultz. Both human and social capital are composed of durable aspects of human behaviour that accumulate through an identifiable production process: the 'household production' of knowledge and social interactions, respectively (Becker, 1996). Both are acquired through a form of effort that 


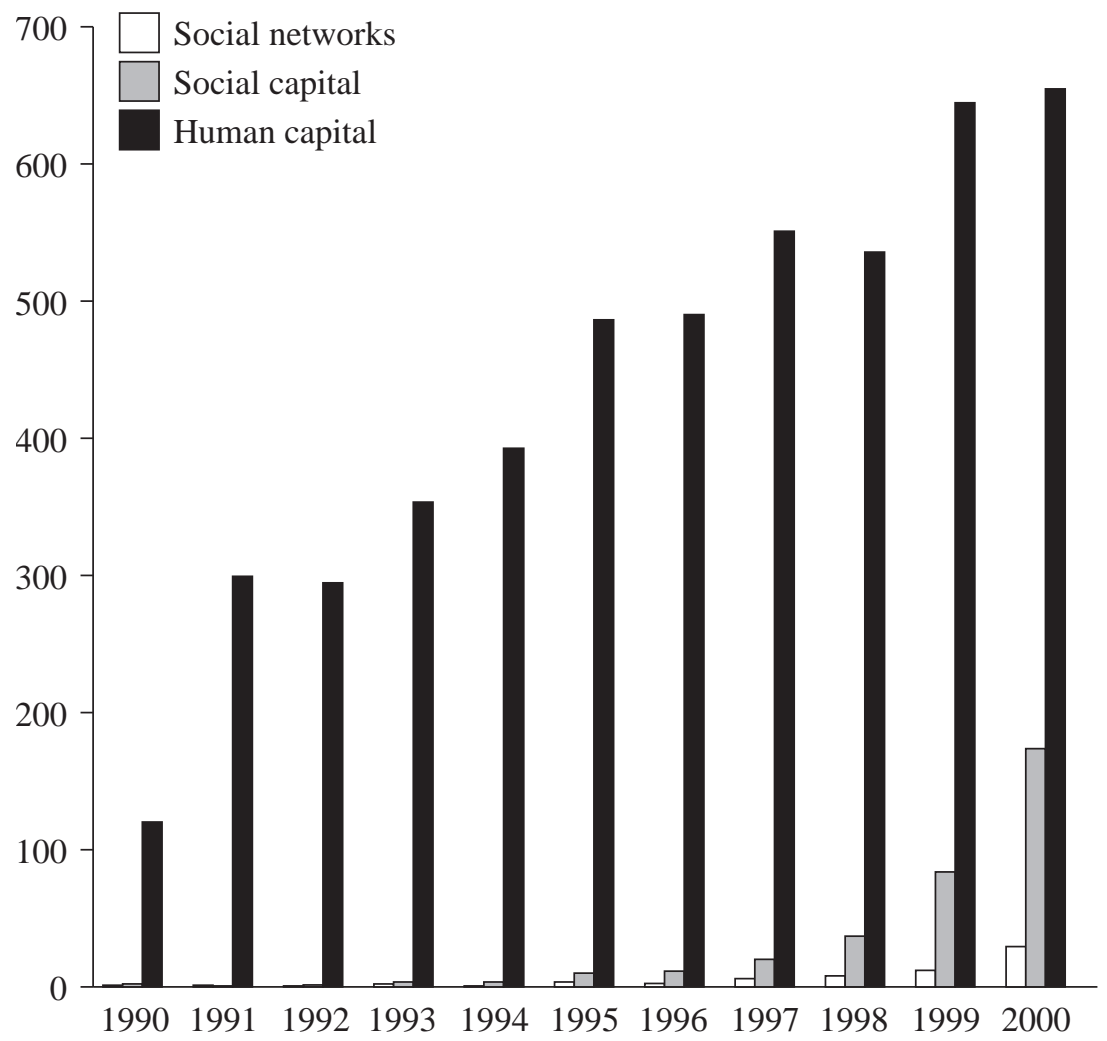

Figure 1.1 Citations with social capital, human capital and social networks in EconLit

puts a limit on their accumulation: knowledge acquisition and social interactions both require time or resources, which are only finitely available. Both exist in a variety of forms: human capital comprises different forms of formal education and on-the-job experience; social capital comprises different forms of social networks and social norms. Both can generate large positive or negative externalities: the accumulation of levels of knowledge and the social networks of one's neighbours can have positive or negative effects on one's own economic decisions. Finally, an economic value can be placed on both: the net present value of the incremental income stream associated with access to knowledge and to recurrent and patterned social interactions, respectively (Collier, 2002).

On the other hand, certain aspects of networks and norms do not capture the 
strict sense of the term 'capital' as applied to physical goods that are factors of production; this is also true for formal education and on-the-job experience. There is certainly no standard way to account for depreciation - how do social networks and stocks of knowledge depreciate without use? (Ostrom, 2000) nor for whether they can be used at different rates. More critically, without a set of market prices to determine their relative value, it is not possible to aggregate social interactions determined by networks and norms into a meaningful measure of a stock of capital (Dasgupta, 2000). ${ }^{2}$

There is related criticism concerning measurement: how can one measure the quantity and quality of social networks and norms, as researchers measure formal education and on-the-job experience? Putnam's pioneering approach (1993) focused on the quantity and quality of associational membership and activity. In the development context, Narayan and Pritchett (1999) and Grootaert et al. (Chapter 5, present volume) exemplify this approach, where the quantity and quality of associational activities are used to test empirically the effect of social capital on different economic outcomes. Indeed, household-level survey instruments are now regularly incorporating measures of social capital: for example, most World Bank household survey instruments have included questions about social networks and norms since the successful 'Local Level Institutions Project' (World Bank, 1998). However, measurement of networks and norms can be troublesome. Glaeser et al. (2000) and Carpenter (Chapter 7, present volume) show how hypothetical and 'warm glow' biases, among others, can cast doubt on self-reported measures of trust and reciprocity.

Of course, the growing acceptance of social capital in the market place of ideas does not imply that critics' questions about conceptual and measurement issues have been completely answered. We are convinced, however, that the concept enhances the analysis of the determinants of well-being in developing countries. Indeed, the growing theoretical and empirical literature on social capital has helped to fuel a resurgence of interest in the social dimensions of development (Woolcock, present volume, Chapter 2). A range of new research shows that communities endowed with a rich capacity to form social networks and adhere to social norms are in a stronger position to resolve disputes (Schafft and Brown, 2000), share useful information (Isham, forthcoming), implement successful development projects (Galasso and Ravallion, 2001) and alleviate poverty (Moser, 1996; Kozel and Parker, 2000).

We believe that Dasgupta (2000) puts it well: 'The concept of social capital is useful insofar as it draws our attention to those particular institutions serving economic life that might otherwise go unnoted. Once attention is drawn to them, we need to try to understand them and find ways of improving them or building around them.' 


\section{SOCIAL CAPITAL AND WELL-BEING}

Development is a process of expanding the real freedoms that people enjoy (Sen, 1999). ${ }^{3}$ In particular, it requires the removal of major sources of 'unfreedom': poverty as well as tyranny; poor economic opportunities as well as social deprivation; neglect of public facilities as well as the intolerance or overactivity of repressive states.

Development enables greater well-being: an expanded set of economic opportunities, better health, more education and greater political and civil liberties. Well-being, as conceived of by Amartya Sen and Partha Dasgupta, is a measure of actual and potential quality of existence: it encompasses both the attainments of an individual and the choices that she enjoys. ${ }^{4}$

Sen (1985) introduced the term in the development context by noting that the quality of a person's existence encompasses 'being' and 'doing' (what Sen calls 'functionings') from an available set of choices (what Sen calls 'capabilities'). For example (as in Grootaert et al. in Chapter 5 of the present volume), the standard of living of members of a family in Burkina Faso can be partially assessed by observing whether the entire family is healthy and the school-age children are literate. The entire family is able to stay healthy because the head of the household has the choice of borrowing from a community lending institution, and school-age children are literate because they have the choice of attending a community-supported school.

Muellbauer (1987) illustrated how Sen's notion of well-being is conceptually related to the household production model. In the household production framework, commodities - the 'primary objects of consumer choice . . that directly contribute to utility' (Michael and Becker, 1973) - are produced by market goods and time. Broadly interpreted, these commodities are similar to the 'functionings' that increase an individual's well-being: they are 'beings' and 'doings' that are chosen from a constrained set of capabilities to function, which are in turn derived from a set of available market goods and services and a set of environmental, physical and social inputs. Again, using the example of a family in Burkina Faso, good health and literacy are 'produced' in part by purchases of household goods and the allocation of family time for health care and school attendance.

We can illustrate the connections among household production, well-being and social capital with one equation that represents the utility of a household that is optimizing over a range of commodities. Let the utility of household $i$ at time $t$ be $U_{i t}=U\left(Z_{i}\left(X_{i}, T_{i}, W_{i}\right)\right)$, where household allocations of vectors of market goods $\left(\mathbf{X}_{\mathbf{i}}\right)$ and time $\left(\mathbf{T}_{\mathbf{i}}\right)$ produce a vector of commodities $\left(\mathbf{Z}_{\mathbf{i}}\right)$ that yields utility. Deaton and Muellbauer (1980) and Betancourt (1996) detail how the environmental, physical and social inputs can be seen as fixed inputs into the household production decision. Accordingly, let $\mathbf{W}_{\mathbf{i}}$ be a vector of fixed 
inputs that affects this production of commodities: these fixed inputs include forms of physical capital, environmental conditions and forms of social capital. For example, a rural household in Indonesia will need to use fewer market goods and less time to obtain clean water when it can depend on productive forms of physical capital (a system of working standposts), good environmental conditions (a reliable water source) and productive forms of social capital (social norms that facilitate collective maintenance) (Isham and Kähkönen, 2002).

In Chapter 3 of the present volume, Paul Streeten distinguishes among different aspects of social capital: consumption goods (non-durable and durable), non-durable production goods, and durable capital goods (for marketed and non-marketed activities). Following the household production framework, these aspects of social capital include commodities that directly yield utility (making a new friend or enjoying activities of a soccer club); productive inputs into commodity production (joining a peasant organization, as discussed by Molinas in Chapter 6 of the present volume); and fixed inputs into commodity production (community lending institutions and effective parent-teacher associations, as discussed by Grootaert et al. in Chapter 5).

Streeten notes that one of the distinguishing aspects of social capital is that these aspects are interdependent: 'we may enter a club for pleasure, companionship, or self-interest but in the process we acquire the trust and the skills that bring substantial economic benefits'. In other words, household production of social investments by an individual in one period - as both consumption and production goods - will accumulate into forms of social capital that are available in future periods, as fixed inputs into future household production by this individual and by others.

Specifically, many forms of privately generated social investments are likely to yield productive spillovers as forms of bonding, bridging and linking social capital. In Chapter 2, Woolcock illustrates how 'bonding' social capital refers to relations among family members, close friends and neighbours; 'bridging' social capital refers to relations among more distant associates and colleagues who have somewhat different demographic characteristics irrespective of how well they know one another; and 'linking' social capital refers to alliances with sympathetic individuals in positions of power. In Chapter 4, Narayan focuses on two comparable aspects of social capital: cross-cutting ties that characterize social relations in informal or formal voluntary groups and networks characterized by heterogeneity of membership that distinguish social groups; and the interaction between formal and informal institutions.

The household production-based view of social capital and well-being is also consistent with the reality that selected elements of the social structure can have negative spillovers (discussed by Streeten in Chapter 3), as in the case of norm reinforcement by the Mafia in southern Italy (Gambetta, 1988). ${ }^{5}$ 
In addition, it is also consistent with the reality that selected elements of the social structure can have positive effects on some economic outcomes and negative effects on other economic outcomes. In some settings village-level ethnic homogeneity may increase intra-village information flows about improved technologies. In the same setting, it may also decrease the resolution of inter-village collective action dilemmas. For example, Grootaert (1999) illustrates how village homogeneity can have both positive and negative effects on economic outcomes in rural Indonesia.

In a manner that is consistent with this conceptual approach, the chapters in this volume explore how social capital - as a fixed input into household production - affects well-being. Many of the chapters focus on one of the four aspects of well-being emphasized by Sen (UNDP, 1990 and subsequent years) and Dasgupta (Dasgupta and Weale, 1992; Dasgupta, 1993): real purchasing power, education, health and freedom to choose.

- Real purchasing power: in Chapter 5, Grootaert et al. present evidence that the incidence of consumption crises in Burkina Faso is substantially lower in villages in which community lending institutions are active. In Chapter 11, Healy demonstrates how social capital in Bolivia, in the forms of democratic assemblies, rule by consensus, rotating leadership and egalitarian ethos, has been mobilized to support the growth of the cacao market.

- Education: in Chapter 5, Grootaert et al. present evidence that community participation in parent-teacher associations in Burkina Faso is associated with substantially higher rates of school attendance.

- Health: in Chapter 10, Daniere et al. discuss how access to sanitation services in five Bangkok slums critically depends on social integration and linkages with external authorities.

- Freedom to choose: in Chapter 8, Cardenas presents empirical evidence from field experiments in Colombia, which shows that voice and loyalty among members within a group improve outcomes through communication and self-government. In Chapter 12, Colletta and Cullen show that conflict in war-torn Cambodia, Guatemala, Rwanda and Somalia has often been caused by social exclusion, inequality and indignity.

\section{INVESTING IN SOCIAL CAPITAL TO IMPROVE WELL-BEING}

Designers and supervisors of development projects and policy can no longer ignore forms of social capital that are likely to affect economic outcomes (Dasgupta, 2000). For example, in villages with high levels of inequality, 
norms that discourage social contacts between the rich and the poor would hinder the flow of public information about agricultural practices from the rich to the poor; in countries with few cross-cutting ties among ethnic groups, public health programmes may be coopted by the controlling elite.

Taking social capital into account, however, poses an immediate challenge to policy makers: how can one assess the composition of social capital in a target area? In Chapter 9, Isham promotes 'social assessments', field-based investigations of the social processes that affect local development outcomes (World Bank, 1996), as a cost-effective means of analysing characteristics of local social structures. In Chapters 7 and 8, Carpenter and Cardenas make the case that experiments among potential recipients of development assistance are a promising method for assessing various forms of social capital. Overall, the information provided by social assessments or experiments can help to provide information on which villages will, ceteris paribus, have higher expected returns to public investments. This is also true at the state level. In Chapter 12, Colletta and Cullen illustrate, with case studies of the four wartorn countries of Cambodia, Guatemala, Rwanda and Somalia, how disastrous conflicts can result from social exclusion, inequality and indignity. The implementation of a country-level development strategy is likely to be more effective when such country-level social conditions are documented and subsequently frame the strategy formation.

Under what guidelines should policy makers act on knowledge gained from assessments of local social structures and of country-level social conditions? First, we underline that one must follow the principle of 'first, doing no harm' (Ostrom, 1990; Narayan and Pritchett, 1999). As noted by Daniere et al. in Chapter 10 of the present volume, complex social relations that exist in even the least socially integrated groups can be detrimentally affected by poorly designed (if well intentioned) planning initiatives. This may be particularly true in very poor communities: households that are struggling to meet basic needs are less likely to respond to incentives designed to create social capital (for example, to gather regularly to initiate and support a local primary school).

In Chapter 4, Narayan stresses that development assistance dedicated to increasing well-being should support existing social organizations and promote cross-cutting relationships among exclusionary groups: this includes investments for building the strength of organizations of the poor and for directly facilitating cross-cutting ties. However, if investments in social capital are to be undertaken - for example, by training a local women's self-help group or by cofinancing a national-level NGO - the expected net benefits of such investments, like all potential development investments, should be compared to the expected net benefits of alternative investments. In Chapter 9 , Isham explores this point by focusing on potential investments in the delivery of local services, like clean water and sanitation. 
In Chapter 12, Colletta and Cullen illustrate how to follow these investment principles in the case of humanitarian relief. They argue that, when local abilities to utilize social capital are identified, humanitarian assistance should strengthen both primary (bonding) social capital and bridging networks. However, international agents should not overload local capacity by giving too much work or money to such efforts: in other words, when the marginal returns to investments in social capital have substantially diminished.

\section{CHAPTER SUMMARIES}

The chapters after this introduction are arranged in the thematic fashion: the history and scope of the concept of social capital in development economics; empirical and experimental evidence on social capital and well-being; and policy implications for investing in social capital in the field. We hope that the contributions in each of these chapters will help scholars, practitioners and teachers to sharpen their analysis of the ways social capital can affect the pursuit of improved well-being in the developing world.

The rest of the chapters in Part I frame the history, scope and the complexities surrounding the use of 'social capital' as it pertains to economic development. In Chapter 2 ('Social capital in theory and practice: where do we stand?'), Michael Woolcock synthesizes the recent theoretical and empirical literature on social capital and economic development. He reviews the challenges of defining and measuring social capital, and discusses the strengths and weaknesses of different disciplinary approaches to the term. Woolcock suggests that proven research strategies - qualitative and quantitative - should inform the design of new instruments to measure social capital, thereby improving our understanding of the way social capital affects well-being. He argues that social capital should provide a framework and a discourse that permits a common conversation among representations from different disciplines, methodologies and sectoral backgrounds. Moreover, he encourages policy makers to support interdisciplinary educational programmes that incorporate 'clean models' and 'dirty hands' and nurture rigorous depth and sympathetic breadth of knowledge about the role of social capital in improving well-being.

In Chapter 3 ('Reflections on social and antisocial capital'), Paul Streeten acknowledges the difficulty of defining, measuring and implementing the concept of social capital, yet exhorts sceptical development economists to take a second look at the concept. To clarify the concept, Streeten argues that social capital comprises consumption goods (non-durable and durable), nondurable production goods, and durable capital goods (for marketed and nonmarketed activities). He emphasizes the potential negative effects of what he 
calls 'antisocial capital' on development outcomes, and then proposes that productive social capital should be nurtured and promoted at a global level. Streeten concludes with a list of novel suggestions for future research in this area.

In Chapter 4 ('Bonds and bridges: social capital and poverty'), Deepa Narayan summarizes theoretical and empirical evidence that shows how the concept of social capital improves the analysis of the social dimension of development. Narayan then focuses on two aspects of social capital: crosscutting ties that characterize social relations in informal or formal voluntary groups and networks; and the interaction between formal and informal institutions. She presents case studies to demonstrate four possible combinations (comprising high and low cross-cutting ties, and well and poorly functioning states) and illustrates how high levels of cross-cutting ties and a well-functioning state best facilitate economic growth and well-being. She argues that outside interventions intended to increase well-being must account for existing social organizations and promote cross-cutting relationships among exclusionary groups.

The chapters in Part II provide empirical and experimental evidence, with different measures of social capital, on critical linkages between social capital and well-being. In Chapter 5 ('Social capital, education and credit markets: empirical evidence from Burkina Faso'), Christiaan Grootaert, Gi-Taik Oh and Anand Swamy empirically examine the effects of different forms of social capital on the performance of educational institutions and the functioning of credit markets in Burkina Faso. Using household survey data, the authors find that community participation in parent-teacher associations is associated with substantially higher rates of school attendance, and the incidence of consumption crises - as indicated by distress sales - is substantially lower in villages in which community lending institutions are active. The authors conclude by suggesting ways to increase active involvement in parent-teacher associations and establishment of stronger active community lending institutions.

In Chapter 6 ('The interactions of bonding, bridging and linking dimensions of social capital: evidence from rural Paraguay'), José Molinas empirically investigates forms of bonding, bridging and linking social capital in rural communities in Paraguay. With survey data from households and peasant committees, he explores the determinants of successful committee performance and attendance as well as peasants' decisions to join a local committee. He shows that informal interactions among households and strong linking strategies of peasant committees can strengthen bridging and bonding social capital, as measured by committee performance and membership attendance. He concludes by arguing that policy makers can catalyse virtuous circles of poverty alleviation by understanding the nature of bonding, bridging and linking relationships in local communities. 
In Chapter 7 ('Measuring social capital: adding field experimental methods to the analytical toolbox'), Jeffrey Carpenter makes the case that laboratory experiments should complement the use of policy-oriented surveys in economics (and other social sciences). Carpenter shows that, while surveys can effectively frame policy-related issues and capture demographic data, economic experiments can validate survey results by providing incentive compatibility to elicit truthful responses. He then details four experiments: the 'trust' game, which measures trust and reciprocity; the 'ultimatum' game, which measures norms of fairness and reciprocity; the 'dictator' game, which measures generosity; and the 'voluntary contribution' game, which measures individuals' propensity to cooperate. While they are designed to test the predictive power of game-theoretic models, Carpenter illustrates how these games can be used to measure forms of social capital.

In Chapter 8 ('Rethinking local commons dilemmas: lessons from experimental economics in the field'), Juan-Camilo Cardenas argues that pessimism about commons dilemmas should be reconsidered in light of recent theoretical models, fieldwork and experimental work on common-pool resources (CPR). With data from field experiments conducted in rural CPR settings in Colombia, Cardenas demonstrates that many institutional factors determine whether groups can approach the socially optimal management of a CPR. In particular, an institutional setting that permits communication among homogeneous agents, without the intervention of a regulator, can promote relatively effective 'governing of the commons'. He concludes by suggesting that policyoriented researchers should design field experiments that encourage active contributions of actual CPR users and that educators should involve students in classroom experiments to create a deeper understanding of sustainable management of a CPR.

The chapters in Part III explore the conditions under which investments in social capital can significantly improve well-being. In Chapter 9 ('Can investments in social capital improve local development and environmental outcomes? A cost-benefit framework to assess the policy options'), Jonathan Isham considers potential investments in development projects whose principal objective is the improved delivery of local services, such as the provision of clean water to a village. In this context, Isham cautions against blindly investing in social capital as a panacea for all development ills. He calls for a cost-benefit-oriented approach to potential investments in social capital that follows three guidelines. First, potential investments in social capital should be considered alongside potential investments in physical and human capital during the planning phase of most development projects. Second, since social capital can be a substitute or a complement to other potentially productive inputs, assessments of prevailing forms of social capital in a target area are likely to be valuable, even when direct investments in social capital are not 
anticipated or called for. Finally, guided by social assessments and the likely benefits and costs of potential investments in social capital, designers of development projects should recommend that investments not be undertaken in certain regions with very low levels of social capital - unless guided by equity considerations.

In Chapter 10 ('Social capital and environmental management: culture, perceptions and action among slum dwellers in Bangkok'), Amrita Daniere, Lois Takahashi and Anchana NaRanong explore the connection between social capital and environmental management in five of Bangkok's urban slums. The authors analyse how the capacity of low-income groups for collective environmental action is affected by geographic locale, income, security of tenure, relationship with other low-income settlements, and forms of social capital. Differences in environmental management among these slums critically depend on differences in social integration and linkages with external authorities. According to the authors, it is critical that the prevailing forms of community-level social capital be assessed prior to project implementation.

In Chapter 11 ('Building networks of social capital for grassroots development among indigenous communities in Bolivia and Mexico'), Kevin Healy presents two case studies of indigenous organizations that utilize social capital to promote grassroots development. The case of $E l$ Ceibo, a Bolivian peasant federation of 37 community-based service cooperatives, demonstrates how democratic assemblies, rule by consensus, rotating leadership and egalitarian ethos have been mobilized to support the growth of the cacao market in Bolivia. The case of museos communitarios, a community-based museum movement in Oaxaca, Mexico, illustrates how external agents have assisted the linking process that supplies the necessary financial capital for the growth of local museums. Healy argues that policy makers must acknowledge the importance of cultural change and thereby consider investments in social capital (such as the training of local personnel) to support this social process.

In Chapter 12 ('Resilient communities: building the social foundations of human security'), Nat Colletta and Michelle Cullen use case studies from four war-torn countries - Cambodia, Guatemala, Rwanda and Somalia - in order to identify conditions that reinforce exclusionary 'bonding' social capital, as opposed to nurturing exclusionary 'bridging' social capital. Colletta and Cullen show how conflict often results from exclusion, inequality and indignity, and then analyse the post-conflict recovery and growth of the four countries. They argue that peace-building efforts, in addition to economic reconstruction and the rebuilding of physical infrastructure, should try to foster social cohesion; and that the development process in these regions must revitalize productive social capital in order to lay the foundations for future sustained improvements of well-being.

We conclude by stressing the need for humility in attempting to define and 
measure forms of social capital and in attempting to assess and invest in social capital. The social dimensions of development are indeed extraordinarily complex. However, in order to improve well-being in developing countries, we think that such attempts are well worth the effort. We believe that the chapters in this volume provide guidance in this difficult but hopeful direction.

\section{NOTES}

1. This search of EconLit was conducted on 20 May 2002.

2. Aggregating all private and public investments is, in theory, a way to measure the increase of an economy's capital stock in a given period. In practice, this too is very challenging, particularly in the context of the developing world. For a discussion, see Pritchett (2000).

3. While Sen's ideas are widely accepted, there are a number of scholars who would argue that 'freedom' is a cultural construct, and the way in which 'freedom of choice' is typically expressed in development economics, and adopted by economists in general, is highly restrictive. Marglin and Marglin (1990) best capture these alternative critiques.

4. Dasgupta (1993) defines well-being as a function of 'utility (because it is the most reliable approximation of her rational desires), and an index of the worth to her of the freedom she enjoys'.

5. In a recent letter to The Economist on multilateral interventions to support civil society, Robert Wade dryly observes: 'Unkind people might observe that al-Qeda is an NGO, and one with extraordinary levels of social capital' (The Economist, 13 October 2001).

\section{REFERENCES}

Arrow, Kenneth J. (2000), 'Observations on social capital', in Partha Dasgupta and Ismail Serageldin (eds), Social Capital - A Multifaceted Perspective, Washington, DC: World Bank.

Basu, Kaushik (1997), Analytical Development Economics, Cambridge, MA: MIT Press.

Becker, Gary (1996), Accounting for Tastes, Cambridge, MA: Harvard University Press.

Betancourt, Roger R. (1996), 'Growth capabilities and development: implications for transition processes in Cuba', Economic Development and Cultural Change, 44 (2), 315-31.

Coleman, James S. (1990), Foundations of Social Theory, Cambridge, MA: The Belknap Press of Harvard University Press.

Collier, Paul (2002), 'Social capital and poverty', in Christiaan Grootaert and Thierry van Bastelaer (eds), The Role of Social Capital in Development, Cambridge: Cambridge University Press.

Dasgupta, Partha (1993), An Inquiry into Well-Being and Destitution, Oxford, UK: Clarendon Press.

- (2000), 'Economic progress and the idea of social capital', in Partha Dasgupta and Ismail Serageldin (eds), Social Capital - A Multifaceted Perspective, Washington, DC: World Bank.

Dasgupta, Partha and Martin Weale (1992), 'On measuring the quality of life', World Development, 20 (1), 119-31. 
Deaton, Angus and John Muellbauer (1980), Economics and Consumer Behaviour, Cambridge: Cambridge University Press.

Galasso, Emanuela and Martin Ravallion (2001), 'Decentralized targeting of an antipoverty program', Policy Research Working Paper no. 2316, World Bank, Washington, DC.

Gambetta, Diego (1988), 'Mafia: the Price of Distrust', in Diego Gambetta (ed.), Trust: Making and Breaking of Cooperative Relationships, Oxford: Basil Blackwell.

Glaeser, Edward L., David Laibson, José A. Scheinkman and Christine L. Soutter (2000), 'Measuring trust', Quarterly Journal of Economics, 65, 811-46.

Grootaert, Christiaan (1999), 'Social capital, household welfare and poverty in Indonesia', Local Level Institutions Working Paper No. 6, World Bank, Washington, DC.

Isham, Jonathan (forthcoming), 'The effect of social capital on technology adoption: evidence from rural Tanzania', The Journal of African Economies.

Isham, Jonathan and Satu Kähkönen (2002), 'How do participation and social capital affect community-based water projects? evidence from central Java, Indonesia', in Christiaan Grootaert and Thierry van Bastelaer (eds), The Role of Social Capital in Development, Cambridge: Cambridge University Press.

Kozel, Valerie and Barbara Parker (2000), 'Integrated approaches to poverty assessment in India', in Michael Bamberger (ed.), Integrating Quantitative and Qualitative Research in Development Projects, Washington, DC: World Bank, pp. 59-68.

Marglin, Frederique and Stephen Marglin (eds) (1990), Dominating Knowledge, Oxford: Clarendon Press.

Michael, Robert T. and Gary S. Becker (1973), 'On the new theory of consumer behavior', Swedish Journal of Economics, 75, 378-96.

Moser, Caroline (1996), Confronting Crisis: a comparative study of household responses to poverty and vulnerability in four poor urban communities, Environmentally Sustainable Development Studies and Monograph Series 8, Washington, DC: World Bank.

Muellbauer, John (1987), 'Professor Sen on the standard of living', in Geoffrey Hawthorn (ed.), The Standard of Living, Cambridge, UK: Cambridge University Press.

Narayan, Deepa and Lant Pritchett (1999), 'Cents and sociability: household income and social capital in rural Tanzania', Economic Development and Cultural Change, 47 (4), 871-97.

Ostrom, Elinor (1990), Governing the Commons: The Evolution of Institutions for Collective Action, New York: Cambridge University Press.

(2000), 'Social capital: a fad or a fundamental concept?', in Partha Dasgupta and Ismail Serageldin (eds), Social Capital - A Multifaceted Perspective, Washington, DC: World Bank.

Pritchett, Lant (2000), 'The tyranny of concepts: CUDIE (cumulated, depreciated, investment effort) is not capital', Journal of Economic Growth, 5, 361-84.

Putnam, Robert (1993), Making Democracy Work, Princeton, NJ: Princeton University Press.

Putnam, Robert (2000), Bowling Alone, New York: Simon and Schuster.

Ray, Debraj (1998), Development Economics, Princeton, NJ: Princeton University Press.

Schafft, Kai and David Brown (2000), 'Social capital and grassroots development: the case of Roma self-governance in Hungary', Social Problems, 47 (2), 201-19. 
Schultz, Theodore W. (1960), 'Capital formation by education', The Journal of Political Economy, 68 (6), 571-83.

Sen, Amartya (1985) 'Well-being. agency and freedom', The Journal of Philosophy, $\mathbf{8 2}$ (4), 169-221.

(1999), Development as Freedom, New York: Alfred Knopf.

Solow, Robert (2000), 'Notes on social capital and economic performance', in Partha Dasgupta and Ismail Serageldin (eds), Social Capital - A Multifaceted Perspective, Washington, DC: World Bank.

Streeten, Paul (1995), Thinking about Development, New York: Cambridge University Press.

UNDP (1990 and subsequent years), The Human Development Report, Oxford: Oxford University Press.

Woolcock, Michael (1998), 'Social capital and economic development: toward a theoretical synthesis and policy framework', Theory and Society, 27 (2), 151-208.

World Bank (1996), World Bank Participation Source Book, Washington, DC: World Bank.

World Bank (1998), 'The local level institutions working study: overview and program description', Washington, DC: World Bank. 